\title{
A framework for deciding on the inclusion of emerging impacts in life cycle impact assessment
}

\author{
S. Cucurachi ${ }^{a, *}$, R. Heijungs ${ }^{\mathrm{a}, \mathrm{c}}$, W.J.G.M. Peijnenburg ${ }^{\mathrm{a}, \mathrm{b}}$, J.F.B. Bolte ${ }^{\mathrm{b}}$, G.R. de Snoo ${ }^{\mathrm{a}}$ \\ a Institute of Environmental Sciences (CML), Leiden University, P.O. Box 9518, 2300 RA Leiden, The Netherlands \\ ${ }^{\mathrm{b}}$ National Institute for Public Health and the Environment (RIVM), Bilthoven, The Netherlands \\ ${ }^{\mathrm{C}}$ Department of Econometrics and Operations Research, VU University Amsterdam, Amsterdam, The Netherlands
}

\section{A R T I C L E I N F O}

\section{Article history:}

Received 22 December 2013

Received in revised form

1 May 2014

Accepted 2 May 2014

Available online 14 May 2014

\section{Keywords:}

LCA

Non-toxic pollutants

Emerging pollutants

Noise

Ecological light pollution

Electromagnetic fields

\begin{abstract}
A B S T R A C T
As technology progresses, so does the concern about the potential health impacts on humans and biodiversity that go in hand with technological development. Emerging new impacts that are characteristic of the anthropocene require more attention in current life cycle assessment (LCA), a framework in which many relevant impact assessment models are still missing. More attention, more data and more concern require the LCA community to intervene and to start or increase the modelling efforts to accommodate new impacts in LCA. To date the process of inclusion of new impacts in LCA has not yet been formalised. To deal with this process, a framework is here proposed and tested through the analysis of three emerging impact categories, noise, ecological light pollution (ELP) and radio-frequency electromagnetic fields (RF-EMF). We show that any development must start from a careful study of the theories and investigations from other specialist fields of science than the field of LCA. The gathering of such information is fundamental to assess the maturity of the impacts, their importance and the quality of the evidence that is available. In addition, this information has to be bridged to the computational structure of LCA, to check whether the physical properties of new impacts may be adjusted to the basics of LCA. We discuss the three new potential impact categories as a paradigm for action for any new development in LCA.
\end{abstract}

(c) 2014 Elsevier Ltd. All rights reserved.

\section{Introduction}

Life cycle assessment (LCA) has developed over the last decade into a diverse and complex scientific discipline that actively involves scientists and practitioners from different fields. The development of the theory and practices of LCA has led to a fully functional methodology, which has become the reference in the sustainability assessment of products and services (EC-JRC, 2011). LCA studies are encouraged in the form of environmental policies or of recommended actions in a growing number of countries around the world (Guinée et al., 2010). A broadly agreed set of principles guides today the process of evaluating a product system throughout its entire life cycle (ISO, 2006), sustained by a constantly expanding series of publications that analyse a wide variety of methodological issues in LCA. Responding to pressures coming from its community of developers and users, the methodology has matured into a tool that answers sustainability questions

\footnotetext{
* Corresponding author. Tel.: +31 (0) 715271478.

E-mail address: cucurachi@cml.leidenuniv.nl (S. Cucurachi).
}

at different scales, according to the problem at hand and the object of the analysis (Guinée et al., 2010).

LCA has been complemented, in a more or less harmonized manner, with capabilities that broaden its scope to quantify economic aspects (Swarr et al., 2011) and social repercussions (Klöpffer, 2012) of a product or service in a life cycle perspective. LCA, or ISO-LCA (ISO, 2006), has also been broadened through attempts to include and measure impacts for the most diverse and composite pathways. The range of impacts included in the framework has increased and includes life cycle impact assessment (LCIA) methods at a different level of development and complexity. Existing impact categories and characterization models, at both midpoint and endpoint levels, have also been expanded, as well as refined and perfected.

Over the years experts have addressed the necessity of expanding the scope of LCA, to include impacts that have not attracted the attention of model developers and to make LCA a comprehensive environmental assessment tool. In Bare and Gloria (2008), the complete taxonomy of impact categories that could be included in LCA is reported in a complete taxonomy. Impact categories are classified at the midpoint, endpoint and damage level. 
Even though the framework has been expanded, most of the impacts reported in the taxonomy are still missing in LCA.

The recent International Reference Life Cycle Data System (ILCD) effort of the European Commission (EC-JRC, 2010a,b, 2011: Hauschild et al., 2013) highlighted major areas of improvement for less developed impact categories, for which no specific methodology could be yet recommended, stressing that an increased perception of the risks also related to non-chemical pollutants has developed in the LCA community. Furthermore, the ILCD handbook specifies that "an open mind towards additional missing impact categories is needed" and other missing categories should be developed (EC-JRC, 2011). Impact categories that fall in the bucket labelled "missing impacts" include noise, nonionizing radiation (e.g. RF-EMF), light (e.g., from greenhouses), odour, desiccation, accidents, salination, impacts of genetically modified organisms (GMO), and erosion. Several shortcomings have limited the modelling effort for some impact categories which have been occasionally or never addressed by LCIA methods (EC-JRC, 2011). The limitations are recognized in the lack of appropriate inventory data, the lack of characterization factors, or the lack of consensus on the characterization model or principles of characterization (EC-JRC, 2011).

The authors classify these impact categories by their level of priority and amount of work needed to perform the modelling activities. The criteria by which these impact categories should be addressed are not explicitly mentioned in the handbook, nor is the scientific background that is at the basis of the impacts. Moreover, the potential lack of significant results from the investigations conducted by other scientific disciplines (e.g. epidemiology), or the lack of a precise knowledge of physical properties, cause-effect chains or dose-response relationships are also not explicitly mentioned as limiting modelling factors in this report, or in the other reference standards and publications used in the field of LCA (e.g. ISO 14044; ISO, 2006).

In this article, we propose a new framework and clear guidelines to be considered for the development of methodologies for new and emerging impact categories in the field of LCA. The newly proposed framework is tested and applied to a set of three underdeveloped or yet-to-be developed impact categories: noise, radiofrequency electromagnetic radiation, and ecological light pollution. All the three categories have been proposed as potential candidate for improvement or development in the LCA framework. Moreover, they share common physical properties (e.g. are nonchemical and not related to a release of matter), and are often cooccurring. We discuss the various aspects to be taken into account before and during the process of developing a characterization model for such impact categories in LCA. The importance of the study of models from the natural sciences (e.g. from the physical, ecotoxicological and epidemiological domains) is presented as part of the framework and analysed with reference to the three case studies. Significant methodological and formal aspects of LCA are presented in relationship with the proposed framework and in relationship with the three impacts used as case studies. Referring to the computational structure of LCA, indications are also given on the scientific limitations of the modelling activity, including possible issues not only at the LCIA level but also at the life cycle inventory (LCI) level.

\section{The selection of a new impact category in LCIA}

\subsection{Mechanisms and strength of evidence}

As Bryson et al. (2007) point out for a methodology to be useful to science it must provide a means of explanation and a mechanism for improving that explanation. A fundamental step of the study of any scientific development is the careful analysis of the specialist literature to identify which theories have been tested and which results have been corroborated by verifications. As much as general, this question pertains any field of science, including LCA. It is not uncommon in this field to borrow theories and models from other fields of science and to embrace them for the use in LCA. In the context of LCIA, the adoption of global warming potential (GWP) and ozone depletion potential (ODP) and the adaptation of the EUSES model for the evaluation of the impact of toxic chemicals have been in this respect trendsetting examples. However, this transition may not be always justified, or supported by evidence.

A developer should verify that the study of an impact is mature enough to be included in LCA, thus if e.g. the specialists that deal with that specific impacts have managed to define clear mechanisms. As in Popper (1963), "one can sum up all this by saying that the criterion of the scientific status of a theory is its falsifiability, or refutability, or testability". A sufficient number of critical tests, attempts of falsification and repetitions are fundamental conditions also for the inclusion of a theory and impact in LCA, especially if they have led to a standard procedure of measuring the impact. Moreover, it must be possible to establish a clear mechanistic link between the stressor and the impacts, which can be further translated into LCI results and an LCIA model respectively. The availability of sufficient information to be included in the LCI databases complements the process and ensures the future use of the methodology in practice, and also contributes to the quantification of potential sources of uncertainty. The modelling of a new impact should also avoid oversimplifying complex mechanisms in order to include them in the LCA framework.

A further analysis of the literature has to identify the extent to which an impact clearly affects a significant part of a population, videlicet human or animal. In this sense, a further distinction may be made between impacts on humans and impacts on biodiversity and ecosystems. Alternative or complementary elementary flows in LCI and pathways in LCIA may be developed for the different target systems: some impacts may be worth the development effort only for humans, or only for biodiversity. Together with the scientific validity of a theory, the magnitude of an impact reflects the urgency of the need of the modelling activity, and may determine a prioritization of a model to another at a precise point in time, as quantified e.g. for humans in terms of the amount of disability-adjusted life years (DALYs; Murray, 1994) that have been calculated for that impact in the world by a recognized agency (e.g. the World Health Organization).

Emerging issues may anticipate the need for the development of a methodology before the relative effects are quantifiable on a larger scale. Examples of such trends regard the long term issue of the by-products of nuclear energy, the consequences of the cultivation of GMO crops, or, more recently, the use of nanotechnologies in multiple applications. Within the current procedures of technology assessment (Cruz-Castro and SanzMenéndez, 2005), the future trends of the effects of an impact should also be estimated as the result of the increase in the diffusion of a new technology. In the future, technology assessment, together with the social and ethical dimensions of a technology (Russell et al., 2010), should investigate the potential of causing new emerging impacts onto humans and biodiversity, and should also focus on the possible enlargement of the scale of impact of known impacts, as a consequence of technology penetration (Geels and Schot, 2007).

Once checks on the validity and importance have provided sufficient evidence of mechanisms, the analysis needs to identify the type of tool that is best to use to measure the impact. Therefore, before considering to develop a methodology within LCA, a developer should verify whether the emission needs to be 
measured and whether the relative impacts are quantified within a global product system at several stages of a life cycle, or only for a local situation of exposure. Even though appealing from a research point of view, the development of a new model must answer to a real scientific and practical need for an LCIA model that will be effectively useful and preferred to other alternative tools (see Udo de Haes et al., 2004, 2006).

\subsection{On the structure of LCI and LCIA: back to the basics}

Once a solid body of information has been gathered from other specialist domains than LCA, the analysis must establish a clear mechanistic link between the stressor and the impacts, which can be further translated into LCI results and an LCIA model respectively. The availability of sufficient information to be included in the LCI databases complements the process and ensures the future use of the methodology in practice, and also contributes to the quantification of potential sources of uncertainty.

From a theoretical and methodological standpoint, all types of impact may be in principles included in LCA (Udo de Haes et al., 2004). The formal description of the different phases of an LCA study defined in the ISO 14040 series of standards and technical reports (ISO, 2006), together with the formalization of the computational structure of the various phases of the framework (see e.g. Heijungs and Suh, 2002), have contributed to define a baseline to which all new developments in LCA may be compared, tested, and contrasted. Therefore, it should be, at least formally, possible to include an impact in LCA in all cases in which a need is identified for the development of a new methodology to expand the scope of LCA. However, the structure of LCA is rather specific and does not always allow for an immediate adoption of models to its formal components.

Two alternative approaches have developed in the field of LCA to assess a system: the attributional and the consequential perspective. The traditional and still most commonly used attributional LCA allows analyzing the status quo of a system, as it is at a specific moment in time. The consequential LCA, on the other hand, is designed to evaluate the consequences of a decision on the system under study (Ekvall and Weidema, 2004). The two perspectives also differ in the way the inputs and outputs of the elementary flows are scaled to a functional unit. In the attributional perspective, the main material flows are described from raw material extraction to waste management using historical data. Following the consequential perspective, one should include the activities the life cycle that are affected by a change in the system, thus taking a marginal approach to account for the causal relationships and future environmental impacts that are triggered by a change in the system (e.g. a change in future demand). At the basis of both types of LCA, the relation to a functional unit sets an intrinsic limit to the type of aspects that can be meaningfully incorporated in the analysis under both perspectives. LCA has a flow character which clearly relates the material inputs and outputs of the product system (Udo de Haes, 2006), or elementary flows. All environmental burdens can be attributed in a consistent way to a functional unit, which allows for a comparison and a scaling of effects.

The procedure of scaling a process to a functional unit may not always be easily accommodated for all impact categories. Thus, it may be more difficult to include new impact categories in LCA if they are not based on inputs to or outputs from a product system (Udo de Haes et al., 2004). The characteristics of any new development in the impact assessment phase should hold a clear relation to a functional unit, which sets a condicio sine qua non for a category to be included in LCIA.

Typically, LCA involves the study of large product systems, with many unit processes, thus many inputs and outputs. A scaling process is needed to quantify the effective needs and flows of the system as a whole, which results in an intricate web of unit processes, many of which depend upon one another (Curran, 2012). A sufficient body of information needs to be recorded at the life cycle inventory (LCI) stage, to guarantee a full understatement of the elementary flows and their correct characterization. The temporal, spatial, physical (e.g. frequency-specific), and other context-specific elementary emission flows need to be carefully defined to take into account the complex systems of biologically-relevant processes that take place and their relevance to the specific situation of exposure of a target subject. A limit may be posed by the sheer nature of the units commonly used to measure the emissions (e.g. the use of a logarithmic unit); hence, a rigorous mathematical formulation should follow the computational and formal structure of LCI (e.g. adaptability to matrix algebra). This fundamental feature should not be overlooked or disregarded during the selection and modelling of a new impact category.

Once the inventory problem is solved, and all care has been taken to accommodate the model to the need of the LCI structure, the developer may move to the determination of a suitable impact assessment model. This model is typically providing the results which will be used for the characterization of the LCI data for a certain impact category. The characterization model is usually a simplified mathematical representation of physical, chemical and biological processes occurring along the cause-effect chain (Curran, 2012). A characterisation factor (CF; Heijungs and Suh, 2002) is provided by the impact assessment model and is usually specific to a substance (i.e. a chemical, or, per extension, any other quantified item in the inventory table), location of emission, location of exposure of the receptor, time of emission or exposure (e.g. day/ evening/night, summer/winter), or any other further specification needed for the impact category under study. CFs for an impact category may be calculated following the classical toxics-based characterization scheme (Rosenbaum et al., 2007), defined for all effect types, compartments, and exposure routes. The so-called midpoint level reflects impact calculations somewhere before the end of the impact pathway, and relates the potential for each stress to cause an interim effect (e.g. acidification measured in hydrogenion equivalents; Curran, 2012). Midpoints are defined at the point in which a variety of substances share common mechanisms, determining a similar type of burden (Jolliet et al., 2004). At the endpoint, the point of comparison between one impact category and another is at the end of the cause-effect chain, at a stage in which no common midpoint is shared and rather areas of protection are approached (e.g. human toxicity health endpoints). When characterization is conducted at the endpoint, it may be easier for a practitioner to grasp the relationship between impacts and indicator results (e.g. loss of crop due to acid rain, instead of acidification potential).

An important simplification for the modelling process regards the assumption that the characterisation function measures a change in impact as a result of a small change in intervention determined by the product system under study, as compared to a large background of environmental interventions (Heijungs and Suh, 2002). A reference condition (e.g. a reference substance) is used to indicate that a marginal change has taken place for an impact category, as a consequence of a marginal emission e.g. of a substance $x$ in a region $y$ (Huijbregts et al., 2000). Therefore, the marginal changes determined by the functional unit on an additional amount of a stressor introduce very small changes on top of a possibly already perturbed background situation. Alternative approaches to the marginal one have been proposed (e.g. abovethreshold in Potting et al., 1998, or a "zero-effect" or an "environmental target" in Huijbregts et al., 2011), may be evaluated case-bycase for the development of a new characterisation model. The 
model that best portrays the impact category under development, may be the one that is recognized by the specialist literature, previously screened, as the reference for the impact under study (e.g. refers to a recognized standard).

Such assumptions need to be matched to the mechanisms that determine an impact, and to the way the fate, exposure, effect, and damage (Rosenbaum et al., 2007) for that impact may be defined. Once again also at the impact assessment level we deal with a structure that sets clear conditions on the modelling process that best accommodates the computational structure of LCA.

\subsection{A stepwise approach}

The considerations detailed in the previous sections may be further formalized to provide the skeleton for a stepwise checklist to be applied for any new development in LCIA. The consideration on the validity and importance of the basic theories, the relation of an impact to a product system and a set of elementary flows, the relation to a functional unit, the computational structure of the inventory and the characterization steps are all considered as sequential stages in the decision support tool shown in Fig. 1. The application of the tool allows to identify which impact to prioritize when considering new developments in LCA.

Two main stages may be identified in the framework: an analysis of the specialist knowledge and an LCA compatibility test. The stages of the analysis conceptually belong respectively to the scientific domain of the classical natural sciences and to that of LCA, and are explicitly bridged by the framework. The two stages of the analysis allow respectively (i) verifying if sufficient evidence is available for a stressor and (ii) to what extent that knowledge allows to deal with the LCI and LCIA phases of LCA. The combination of these two piece of analysis allows to discern between suitable and non-suitable impact categories in LCA.

In the first stage, the specialist literature in the field of the impact category under study is screened and analysed (step 1 ). The investigation of the literature focuses on the verification that sufficient evidence is available to confirm the mechanistic links between cause and effect, and that a cause-effect chain may be defined to link e.g. an emission to the impact that it has on a target subject. A thorough investigation and study of the specialist literature is advised. This process should involve the consultation of experts from the field of science by which the impact has been already investigated. A close collaboration with the scientists (e.g. ecotoxicologists, epidemiologists) The lack of agreement between relevant experts may be considered as a limiting factor for the development of a new impact. In all cases peer-reviewed publications and reports commissioned by internationally-recognised agencies should be preferred to the so-called grey literature.

In step 2, a suitable model is selected based on a standard, or on theories which have gone through sufficient rigorous validation. The model may refer to a reference standard for the propagation of an emission in a specific compartment (e.g. propagation of sound waves in air). The impact-specific physical properties (e.g. reflection, attenuation, deposition, absorption) are at this stage identified and classified. The theory should allow for the definition of a clear link between the physical properties of the impact and the effect that the impact has on the target-subject under study (e.g. by means of a dose-response relationship). The model developer may not proceed any further if clear mechanisms are not yet clearly known or supported by sufficient scientific evidence.

The importance of the impact is compared to others basing on the data provided by an international organization or by a peerreviewed reference in the field (step 3). The importance should be used as a metric to prioritize the development of new impacts, and may be recursively re-evaluated if new evidence is available. A sufficient information should be available to deal with the collection of data and the need for the quantification of the impacts related to activities in a life cycle. The model developer should verify that there is a need to effectively quantify the impact across a life cycle, thus that LCA provides an added value compared to other environmental assessment tools.

In step 4 the information gathered is tested to verify whether a model should be developed to quantify impacts to each specific area of protection. The evidence and the theories that regard the effect of the impact on humans are gathered. Additionally, in step 4 the modeller evaluates the relationship between the impact under scrutiny and the natural environment, involving non-human life and biodiversity. The measure of biodiversity impacts also includes genetic diversity, species diversity, and ecosystem diversity (Udo de Haes et al., 2002). Finally, the modeller may evaluate if the impact is related to resources that are extracted physically for human use (i.e. abiotic resources such as fossil fuels, or biotic resources such as wood; Udo de Haes et al., 2002).

In the second stage of the process, the identified model and the body of information that has been gathered is tested for its applicability to the LCA computational structure, both at the LCI inventory phase and at the compulsory steps of LCIA (step 5, step 6). The mechanisms behind the emission and the impacts of the selected model are compared to the basic components of LCA as previously described. At first the analysis and development should deal with defining a model at the midpoint level of the impact pathway, closer to the environmental interventions. Once enough information has been gathered at the midpoint also in terms of additional uncertainty added, the model may be complemented to cover the complete impact pathway to the endpoint. The process ends with the definition of the items to be recorded in the inventory table and the identification of the best characterisation model.

The proposed checklist will be tested in the following Section 3 with a selection of emerging impact categories.

\section{Analysis and empirical illustration with case studies. Application of the framework to new or underdeveloped impact categories}

\subsection{The case of the noise impact category}

\subsubsection{The evidence from the literature as a measure of importance and priority (Steps 1-4)}

Noise relates to the exposure of a target to unwanted or disturbing sound produced by a static or mobile source. The exposure of humans to noise has been linked with sufficient scientific evidence to hearing impairment and tinnitus, hypertension, ischemic heart disease, annoyance, sleep disturbance, and decreased school performance (Passchier-Vermeer and Passchier, 2000; Fritschi et al., 2011). It has been quantified that all of these burdens contribute to the loss of at least one million healthy life years every year from traffic-related noise in the western part of Europe (Fritschi et al., 2011). Hollander et al. (1999) calculated a higher number of DALYs lost in the Netherlands from the exposure noise than from any other of the environmental factors considered (e.g. ozone air pollution, particulate air pollution). Dose-response relationships have been quantified for various levels of noise and potential effects have been demonstrated, especially with respect to annoyance and to heart conditions. The majority of the human population in the entire world is deemed to be exposed to noise levels that the WHO considers unhealthy (Stewart et al., 2012).

A considerable body of research also regards the impacts of the effect of anthropogenic noise on animals. Human activities associated with high levels of anthropogenic noise modify animal 


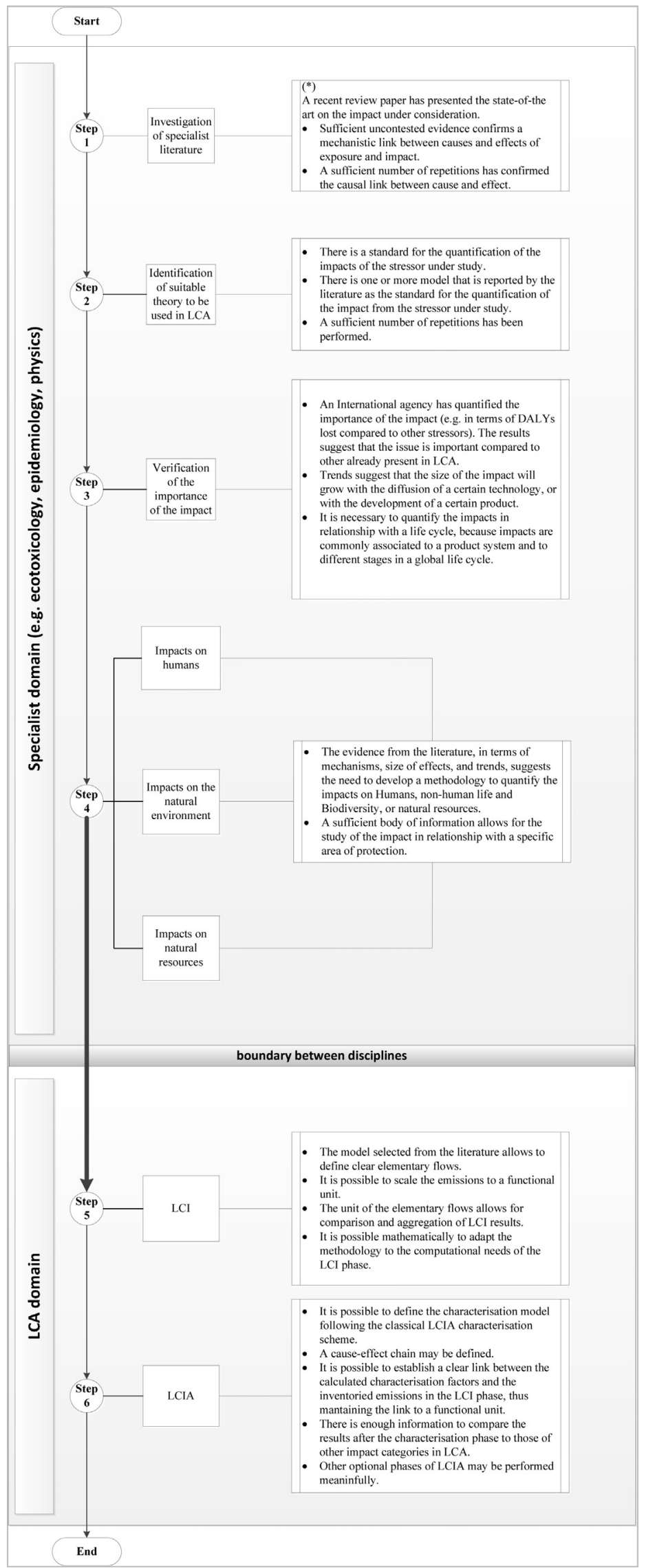

Fig. 1. Decision criteria for the development of new impact categories in LCA. $\left({ }^{*}\right)=$ criteria not mutually exclusive. 
ecology of aerial, terrestrial and water organisms (Halwerk et al., 2011; Barber et al., 2010; Fewtrell and McCauley, 2012). A work by Francis et al. (2012) has brought noise into community ecology, showing evidence that the exposure even alters fundamental ecological services such as pollination and seed dispersal, thus also having ripple effects on plant distribution and community structure (Chan and Blumstein, 2012). Anthropogenic noise is proved to alter acoustic environments determining shifts in animal communication, stress and behaviour especially in urban and road-side communities (Warren et al., 2006; Bee and Swanson, 2007; Parris and Schneider, 2009). Exposure to noise increases levels of stress even in the case of captive-held endangered species (Owen et al., 2004). Studies suggest that noise contributes to quality of territories and affects the behavioural ecology of territorial birds (Brumm, 2004). The exposure to noise plays a role in the shaping of the structure, diversity and density of urban bird communities, and has a direct impact on avian acoustic signals of territory defence, mate attraction and reproductive success (Halfwerk et al., 2011).

\subsubsection{Relationship to LCA and the necessity to quantify impacts in relationship with a life cycle}

Several phases of a life cycle may be associated with the productions of sound that can be perceived as noise. LCA often deals with product systems that involve activities that are typically sound-intensive, e.g. transportation, pile-driving, manufacturing, but it also comprehends the analysis of the use-phase of the life cycle of products when users are e.g. operating a machine determining the production of potentially harmful sounds. The appearance of noise in the LCA scientific discussion dates back to the early years of the methodology (Heijungs et al., 1992). Since then, several efforts have tried to incorporate noise in LCA, usually with a focus on transportation noise and the consequent human health effects (see e.g. Müller-Wenk, 2004; Althaus et al., 2009). A list of CFs and appropriate inventory data are not available in commonly used databases (Cucurachi and Heijungs, 2014). The ILCD handbook identified the noise impact category as one of the stressors with a high modelling priority, with a limited time effort required for its development (ILCD, 2010). The necessity of quantifying the burdens of noise on biodiversity has to date not been dealt with within the field of LCA.

3.1.2.1. The design of an appropriate functional unit (Step 5). A logarithmic decibel $(\mathrm{dB})$ scale is commonly used in the study of sound emissions and noise impacts. The $\mathrm{dB}$ may refer to either a sound pressure level (i.e. related to a pressure in pascal) or a sound power level (i.e. related to a power in watt; Passchier-Vermeer and Passchier, 2000). In order to consider the time a unit process is working for the functional unit, a sound power (i.e. sonic energy per time unit) in watt (i.e. $\mathrm{J} / \mathrm{sec}$ ) may be attributed to any source in the life cycle, by back converting the relative sound power level in dB using logarithmic algebra (Cucurachi et al., 2012; Cucurachi and Heijungs, 2014). Sound power is not location-dependent, but it belongs strictly to the sound source, therefore it perfectly suits the needs of LCI. Once the sound power is available, for each elementary flow in the life cycle it is possible to calculate the relative sound energy in joule to be inventoried in an inventory table.

3.1.2.2. LCIA model and pathway (Step 6). A screening of the specialist literature revealed the presence of established standards for the propagation of sound through a medium (Cucurachi et al., 2012; Cucurachi and Heijungs, 2014). These include the ISO 96131 and ISO 9613-2 and may be used for the evaluation of sound propagation through air. The standards allow for the quantification of the sound pressure that reaches a target at a defined distance from a source, as a function of the sound power of the source and the ambient sound power. A series of attenuation and directivity factors intervene and determine the transition from sound power to sound pressure (Cucurachi and Heijungs, 2014). The ISO standards allow for the definition of the fate factor. An effect factor, specific to the target subject under consideration, may be defined by quantifying the number of individuals living at the exposure compartment. Extra conditions are introduced to account for the species-specific perception of sound at difference frequencies and time (Passchier-Vermeer and Passchier, 2000; Fritschi et al., 2011). For the case of humans, the fate and effect factors are used to obtain characterisation factors for noise impacts on humans following the ISO 9613-1 and ISO 9613-2 and the human perception of sound in air. Characterisation factors allow at a midpoint level to calculate noise impacts from sound emitted by any source. In order to quantify a damage to the endpoint Cucurachi and Heijungs (2014) propose to move from the midpoint to the endpoint by means of a conversion factor that allows for the transition from an abstract unit of person $x$ pascal $x$ second to the DALY scale.

Specific frequency bands, sensitivity factors and penalties may be used for other targets (e.g. birds). Principles of underwater acoustics (e.g., reverberation, salinity of water) need to be considered for sound travel and attenuation in water. If the analysis needs to deal with animal targets, the conversions and calculations vary and the process requires the use of a species-sensitive biodiversity index to move to the specific area of protection.

\subsection{The case of the (radio-frequency) electromagnetic pollution impact category}

\subsubsection{The evidence from the literature as a measure of importance and priority (Steps 1-4)}

The generic term "electromagnetic radiation", as used by the ILCD report (EC-JRC, 2011), identifies a vast area of scientific knowledge which spans over several disciplines, physical properties and physical scales. The expression may as well refer to a system of natural sources of electromagnetic radiation, discharged in the earth's atmosphere by terrestrial and extra-terrestrial sources, such as thunders or the sun, to which the creatures of planet earth have always been exposed. The spectrum of electromagnetic radiation is rather complex and it extends, in fact, from extremely low frequencies with wavelengths in the range of $\mathrm{km}$ to gamma rays with wavelengths of the size of an atom. Radiation can be divided into non-ionizing radiation (radio waves, visible light and heat) and ionizing radiation (e.g. measured in Röntgen) that has sufficient energy to ionize an atom, breaking chemical bonds (Møller and Mousseau, 2013).

We focus in the context of this contribution on the effects of RFEMF on humans and biodiversity, therefore on the range of the man-made electromagnetic fields of the electromagnetic spectrum many orders of magnitude above the natural background. The frequency ranges of interest are in the range of about $3 \mathrm{kHz}-$ $300 \mathrm{GHz}$, with wavelengths ranging from hundreds of kilometres to about one millimetre. The main sources of RF-EMF are broadcasting transmitters (radio and television), mobile phone base stations, devices for wireless communication (e.g. cell phones, DECT phones and wireless LAN/WiFi), navigation and detection devices (e.g. radar, RFID chips, anti-theft portals), industrial machinery (e.g. plastic welding, dielectric heating, induction ovens), medical devices (e.g. MRI, hyperthermia; Baliatsas et al., 2012). All of the aforementioned sources can contribute to human exposure, with the weighted average exposure being mainly from own mobile and cordless phone use.

Apart from (local) heating of tissue, no other short term adverse health effect has been scientifically established (IARC, 2013). Some 
publications suggest that exposure to RF-EMF can have various biological effects from modulated RF-EMF, particularly at lowfrequency modulated fields. However, to date neither plausible biological mechanisms, nor systematic or dose-dependent alterations have yet been identified. The International Committee on Non-Ionising Radiation protection (ICNIRP) published two sets of guidelines for limiting exposure for the general public and for workers (ICNIRP, 1998). These limits have been included in European Recommendation (1999/519/EC) for protection of members of the general population and in the European Directive for the protection of workers. beyond the effects of temperature elevation, it is still unclear how RF-EMF below recommended exposure limits could adversely affect the health of humans (and of other organisms, Lerchl, 2011). The recent IARC (2013) monograph on the effects of RF-EMF states that RF-EMF cannot produce physiological effects at temperature increases smaller than one degree centigrade, thus, in the range of thermal noise below measureable heating.

Sources such as mobile-phone base stations, electric power generators, transmitters, broadcast antennas, affect also other target systems (e.g., insects, birds; Baan et al., 2011). As reported by the WHO (van Deventer et al., 2011) a number of in vitro and in vivo studies of RF-EMF genotoxicity and effects on animal gene and protein expression have been carried out with mostly negative results. Cellular studies and studies on a number of animal models have found significant effects, which, however, have not been replicated or which did not provide dose-dependent responses (Feychting et al., 2005). Animal models, especially rats and mice, have been widely used to investigate potential effects of RF-EMF on humans. A review by Cucurachi et al. (2013) tried to link to ecological implications the biological evidence gathered from the review of RF-EMF animal studies, without finding significant evidence of a clear dose-response relationship for any of the analysed species group.

\subsubsection{Relationship to LCA and the necessity to quantify impacts in relationship with a life cycle}

Frischknecht et al. (2000) proposed a possible pathway for the inclusion of the impacts of ionizing radiation on human health in LCA, and measured the actual burden of radioactive emissions in terms of loss of life years in the population. Non-ionizing electromagnetic radiation, including RF-EMF, has to date failed to attract the attention of the LCA community. The transmission of electricity by means of power lines, or any other product group involving electricity production and use (see Huijbregts et al., 2008) are an example of a possible elementary flow of interest for LCA with respect to the impacts of RF-EMF. For higher frequencies, it would be interesting to analyse the use phase of a mobile device, basestation, or any other broadcasting device. Occupational exposures examples of interest include RF PVC welding machines, plasma etchers, and military and civil radar systems, all operating at different frequencies (IARC, 2013).

3.2.2.1. The design of an appropriate functional unit (Step 5). The exposure to RF-EMF, as reported by the ICNIRP (2010), is usually specified in terms of physical characteristics such as modulation (continuous wave or pulsed), incident electric-field and magnetic-field strengths, incident power density (when appropriate), source frequency, type and zone of exposure (near or far field), and duration of exposure. Suitable information about these features of the exposure should be stored at the LCI phase to allow for a complete analysis of the relationship between source and target system(s).

In the context of dosimetry, the exposure of biological systems to non-ionizing radiation is estimated by means of specific absorption rate (SAR), in watt per kilogram (W/kg). A suitable conversion would have to be used to derive a convenient unit to meaningfully aggregate electromagnetic emissions over a life cycle and to connect them to a functional unit. The knowledge of the SAR allows for the quantification of the electric field strength in relationship to the density of the absorbing medium under consideration, and provides a good estimate of the temperature of the system with which it is very closely correlated. For the LCI phase, the experimental measurement or estimation of the SAR could be the relevant quantity to inventory, along with the electrical properties and wave characteristics of the source under study. The knowledge of these elements would allow to later analysing any possible mechanism of interaction independently of the source of the RF-EMF under study. A convenient definition of the elementary flow would allow for all the relevant information to be carried to next phases of the LCA. The duration of exposure as function of the time a functional unit is active in the system would provide a fundamental information to allow making a hypothesis of possible health effects.

3.2.2.2. LCIA model and pathway (Step 6). There is no known mechanism by which RF-EMF might assert biological effects in humans or other systems, beyond the induction of local heating by RF-EMF (IARC, 2013). Moreover, as Röösli et al. (2008) reports there is limited knowledge on how to combine high, periodic local exposure from sources close to body (e.g. mobile phone) with lower, continuous whole body exposure from environmental fields (e.g. mobile phone base station). Therefore, for the potential modelling of RF-EMF impacts a modeller could only represent at the current state of knowledge only the fate step of the complete impact pathway. The relationship between RF-EMF energy and biological systems is based on the induced electric and magnetic fields, the power deposition, energy absorption, and the distribution and penetration of the energy into biological tissues (ICNIRP, 2010). The exposure of a whole body or part of the body to a given field strength, if enough information was to be reported in the $\mathrm{LCI}$, would have to be considered, and would certainly represent a complicating modelling factor. As in ICNIRP (2010), a quantitative understanding of biological responses to the exposure can be obtained if dosimetric quantities such as SAR, induced electric field, and current density, can be correlated with the observed phenomenon, thus with the relevant flow in the life cycle under study.

Computational algorithms may be used to define fate and exposure analyses and to link dosimetric values with other physical characteristics of the field (e.g. the distance from the source of emission of the RF-EMF to the target, potential dissipation of energy, and the size of the exposed population; ICNIRP, 2010). The lack of accepted mechanisms, dose-response relationships, and disability weighting scales/damage functions limits the possibility to bring the analysis further at the current state-of-the-knowledge. Therefore, the modelling of the impacts of RF-EMF cannot be tackled beyond the LCI phase and the fate step of LCIA, for both the cases of human and non-human exposure.

\subsection{The case of the ecological light pollution impact category}

\subsubsection{The evidence from the literature as a measure of importance and priority (Steps 1-4)}

ELP refers to the condition of direct glare, chronically increased illumination, and unexpected fluctuations in lighting due to a number of sources in cities, towns, industrial sites, and off-shore enlightened locations (Longcore and Rich, 2004). These may include lighted buildings, lights on vehicles, flares on offshore oil platforms, lights on undersea research vessels, highly lighted fishing and cruise fleets, and sky glow (i.e. the brightening of the sky 
beyond background levels due to reflected light; Longcore and Rich, 2004; Navara and Nelson, 2007). The autonomous or interactive effect of these sources may affect humans and ecosystems to varying degrees. It has been estimated that $19 \%$ of the earth surface and about two-thirds of the world population live in areas where the night sky is above the threshold set for polluted status, with 99\% of European and American citizens experiencing nightly light pollution (Cinzano et al., 2001).

The chronic exposure to light at night (LAN) of shift workers has been linked to an increased incidence of breast and colorectal cancers, as a consequence of disruption of hormone production, and especially of the suppression of the antioncogenic agent melatonin and/or of disruption of clock gene function by open eye exposure to LAN (Schernhammer and Schulmeister, 2004; Pauley, 2004; Haim and Portnov, 2013). The link between LAN and breast cancer is now officially recognized by the WHO and the American Medical Association (Bedrosian et al., 2013). The exposure to LAN has also been linked to serious effects on mood of vulnerable individuals, directly by studies on humans or from evidence gathered from rodent studies on mice and hamsters (Bedrosian et al., 2013). Recent studies found evidence of a possible link between LAN and obesity (Fonken et al., 2010; Eckel-Mahan and Sassone-Corsi, 2013), and between LAN and diabetes (Marcheva et al., 2010).

A growing body of research regards the impacts of artificial light on biodiversity and ecosystems. The exposure to ELP may have critical effects on the natural day-night cycle of insects, amphibians, fish, birds, bats and other animals (Longcore and Rich, 2004; Rich and Longcore, 2006; Hölker et al., 2010; Perkin et al., 2011; Gaston et al., 2013). Ecological impacts of ELP have been proven to determine a cascade of alteration of physiological and behavioural processes and determine a series of yet to be fully known consequences on natural ecosystem processes (Gaston et al., 2013).

\subsubsection{Relationship to LCA and the necessity to quantify impacts in relationship with a life cycle}

ELP is absent from LCA studies, though the quantification of its impacts may be of interest for selected life cycles. For the impacts on humans, activities involving night shifts or rotation of shifts may be considered as contributing to possible burden on human health, e.g. from the alteration of the hormone secretion system of individuals exposed to LAN. Impacts on mood alternation and sleep disturbance of individuals may also be considered for selected functional units.

A possibly wider application regards the quantification of impacts due to LAN on biodiversity (e.g. the loss of biodiversity due to exposure to LAN and sources of artificial light). The impacts of ELP (including LAN) may be considered for the LCA of streetlight technologies, lighting products, or for lights in commercial, industrial and residential premises, greenhouses, or illuminated vessels or oil platform in open sea. For the case of alternative lighting options (e.g. incandescent lamp vs. LED lamp), the potential impacts of the specific wavelength, intensity and brightness of the lighting systems may constitute an extra issue to be addressed, not yet considered in current LCA studies. Different forms of artificial lighting increased spatial, temporal and spectral distribution over the recent decades, and have, as reported by Gaston et al. (2013), unique spectral signatures all potentially influencing evolutionary and ecological processes.

3.3.2.1. The design of an appropriate functional unit (Step 5). A sudden change in illumination over the absolute illumination levels is considered by ecologists as disruptive for human and some species (Longcore and Rich, 2004). The determination of illumination (i.e. incidence of light per unit of area) in a given place (Longcore and Rich, 2004) is one the most common measurement of ELP. Illumination is often measured in lux, an SI unit, which is the measure of the perceived power of light per unit of area, thus corresponds to 1 lumen per square meter. The emphasis of the measure is on wavelengths that the human eye is more capable to detect, thus on brightness as perceived by the human vision. In most cases, lux is the standard way used by producers of equipment, or by policy makers to communicate about light conditions.

In the case of biodiversity, supplementary biologically-relevant information is needed to fully understand the impact of ELP. As stated by Longcore and Rich (2004), the impact of the phenomenon on biodiversity is fully understood only if also further biologicallyrelevant information is available, such as the intensity of the light (i.e. number of photons per unit area) and its spectral content (i.e. wavelength). Therefore, the elementary flows in the LCI table would ideally include all the above information. A more suitable unit for non-human targets is the radiant flux of the emitting source, which indicates the total electromagnetic power emitted by a source. The measure (also called radiant power) corresponds to the radiant energy per unit time and its unit is the watt. Therefore, the scaling of the emission to a functional unit, basing on the time the source is active in the system would heed results to be inventoried in units of radiant energy, thus joule. The unit could be used in combination with the functional unit expressed in hours of use or lumen hours commonly considered in the existing LCA of lightemitting devices (see e.g. Tähkämö et al., 2013).

3.3.2.2. LCIA model and pathway (Step 6). The literature on ELP is vast but lacks a synthesis within a common mechanistic framework (Gaston et al., 2013). For the case of humans, it would be challenging and uncertainty-prone to link the effects of ELP and LAN to available statistics on cancer and to a human-health factor in a suitable scale, e.g. DALY. A possible pathway is proposed by Bedrosian et al. (2013) and regards the potential influence that the exposure ELP may have on the circadian rhythm and mood of human beings, and it is based on the functioning of the human eye and its relationship to melatonin secretion.

The prediction and modelling of ELP over a location of interest may present some challenging computational and methodological issues. The ELP of a local atmosphere depends as stated by Kocifaj (2011) "on the size, shape, spatial distribution, radiative pattern and spectral characteristics of many neighbouring light source" and also from distant sources. Local atmospheric and physical conditions are also relevant influencing factors (Kyba et al., 2011). Theoretical assumptions would be necessary, since the total radiative pattern would vary from location to location.

Kocifaj (2007) proposes a scalable theoretical model of light pollution for ground sources, which takes into account the influence of local atmospherical conditions on the transmitted radiation (e.g. the impact of clouds on the light-pollution situation under study). The parametric model, tested also for planar ground-based light sources (Kocifaj, 2008), may be used in the context of LCIA to define fate and exposure factors for light pollution to be linked to the specific defined elementary flows. The model, originally not specifically developed for the ecological implications of light pollution, would have to be adapted to work with any possible LCArelevant source of light and to further link the altered conditions of the background lightscape (as available from e.g. Cinzano et al., 2001; or Bierman, 2012) to an extra functional unit of the source of light under study. The feasibility of the approach needs to be further studied due to the necessity of dealing with highly-localised conditions of exposure.

As in the case of RF-EMF, though the relationship between the emissions of light and its propagation could be modelled, the absence of clear mechanisms would not allow to further define a complete impact pathway, thus a suitable LCIA model. 
Table 1

Synthesis of applied framework on the three potentially relevant impacts.

\begin{tabular}{|c|c|c|c|c|c|c|c|}
\hline Stressor/impact & $\begin{array}{l}\text { Mechanistic effects } \\
\text { (Steps 1-2-3) }\end{array}$ & $\begin{array}{l}\text { Impacts on } \\
\text { humans } \\
\text { (Step 4) }\end{array}$ & $\begin{array}{l}\text { Impacts on } \\
\text { the natural } \\
\text { environment } \\
\text { (Step 4) }\end{array}$ & $\begin{array}{l}\text { Impact on } \\
\text { natural } \\
\text { resources } \\
\text { (Step 4) }\end{array}$ & LCI (Step 5) & LCIA (Step 6) & $\begin{array}{l}\text { Recommended } \\
\text { extent of } \\
\text { modelling } \\
\text { effort }\end{array}$ \\
\hline Sound/noise & $\begin{array}{l}\text { Dose-response } \\
\text { relationships have } \\
\text { been quantified for } \\
\text { humans and selected } \\
\text { species }\end{array}$ & Highly relevant & Highly relevant & - & $\begin{array}{l}\text { Sound power } \\
\text { converted to } \\
{[J] \text { by means }} \\
\text { of time }\end{array}$ & $\begin{array}{l}\text { Defined pathway } \\
\text { for noise impacts } \\
\text { on humans. To be } \\
\text { developed for } \\
\text { biodiversity. } \\
\text { Characterisation } \\
\text { factors for the noise } \\
\text { impacts on humans } \\
\text { expressed in unit of } \\
\text { person } \mathrm{xa} / \mathrm{W}\end{array}$ & $\begin{array}{l}\text { Modelling possible } \\
\text { to midpoint for } \\
\text { human targets. } \\
\text { For the case of } \\
\text { biodiversity, } \\
\text { further studies } \\
\text { should be } \\
\text { conducted }\end{array}$ \\
\hline $\begin{array}{l}\text { RF-EMF emission/ } \\
\text { RF-EMF } \\
\text { pollution }\end{array}$ & $\begin{array}{l}\text { No adverse health } \\
\text { effect, beyond heating } \\
\text { for humans. No strong } \\
\text { evidence of a clear } \\
\text { dose-response } \\
\text { relationship for } \\
\text { any of the analysed } \\
\text { species }\end{array}$ & $\begin{array}{l}\text { Contrasting } \\
\text { evidence. } \\
\text { Classified as } \\
\text { carcinogenic } \\
\text { by IARC }\end{array}$ & $\begin{array}{l}\text { Potentially severe } \\
\text { effects, but lack } \\
\text { of repetitions }\end{array}$ & - & $\begin{array}{l}\text { SAR [W/kg] to } \\
\text { be converted to } \\
\text { a suitable unit to } \\
\text { allow for aggregation } \\
\text { and scaling to the } \\
\text { functional unit }\end{array}$ & $\begin{array}{l}\text { Only fate factor may be } \\
\text { modelled based on the } \\
\text { physical properties of } \\
\text { electromagnetic waves }\end{array}$ & $\begin{array}{l}\text { Modelling not } \\
\text { possible at the } \\
\text { current state } \\
\text { of knowledge } \\
\text { for the complete } \\
\text { impact-pathway }\end{array}$ \\
\hline Light emission/ELP & $\begin{array}{l}\text { Demonstrated for } \\
\text { humans and animals } \\
\text { through melatonin } \\
\text { mediation. }\end{array}$ & $\begin{array}{l}\text { Evidence available } \\
\text { in occupational } \\
\text { contexts }\end{array}$ & High & - & $\begin{array}{l}\text { Light power } \\
\text { converted } \\
\text { to J by means } \\
\text { of time. }\end{array}$ & $\begin{array}{l}\text { Only fate factor may be } \\
\text { modelled based on the } \\
\text { physical properties of } \\
\text { light waves }\end{array}$ & $\begin{array}{l}\text { Modelling not } \\
\text { possible at the } \\
\text { current state of } \\
\text { knowledge for } \\
\text { the complete } \\
\text { impact-pathway. }\end{array}$ \\
\hline
\end{tabular}

\section{Discussion}

For certain life cycles it is the sheer lack of a good model that determines that a flow does not have an impact in a system under study. For instance, it has been claimed that the inclusion of the impacts from noise in some LCA studies may change their final outcome (EC-JRC, 2011; Cucurachi et al., 2012), highlighting other hotspots than the ones that the latest version of the commonly used databases may yield.

In this paper, we show that an increasing awareness about potentially harmful effects of certain impacts does not necessarily lead to their immediate inclusion in LCA. The application of the proposed selection criteria needs to guide the developer in deciding which impacts at a specific moment in time are to be privileged. The methodological limitations of the framework of LCA and the physical complexity of the laws regulating the phenomena under study are key elements to analyse before engaging in any new development in LCIA.

The non-toxic impacts analysed in this contribution all share a common physical nature, which relates to energy that shows a wave-like behaviour as it travels through space or through a medium. Though holding similar features, the detailed study of each of the stressors reveals unique and rather different modelling needs, and, interestingly, a different state of knowledge that scientists have about the complex mechanisms that influence the way these emissions may potentially be harmful for living organisms. The outcome of this study (see Table 1) provides a first approximation of what to take into account when dealing with new impact categories, and in particular with noise impacts, RF-EMF impacts and impacts of ELP.

A first screening of the literature in all cases presented with a clear evidence of potential harmful effects. All impacts are clearly relevant and necessitate of attention also from the point of view of the LCA community, due to their potentially severe impacts on humans and/or biodiversity. However, from a methodological point of view, the mechanisms that lead to the determination of effects are not always fully known or do not always find a consensus in the specialist scientific community of reference.
Of particular interest in this sense, are the impacts from the exposure of organisms to RF-EMF: no clear mechanisms, beyond temperature elevation, have been identified. The literature does not exclude the potentially carcinogenic effects of RF-EMF on humans, but contrasting evidence has been found (IARC, 2013). In this case, the lack of a protocol of exposure and measurement, the design of studies, the limited sample size of the studied populations and the existence of confounding variables have hampered progress to date and do not allow to define clear mechanisms. A case-by-case analysis of a certain species or family is necessary to conclude on specific mechanisms. The analysis of the specialist noise literature provides a clearer picture, with mechanisms and size of the effects defined for both humans and some species birds or sea mammals, which have interested a number of studies of high quality. Finally, the study of the ELP suggests that, for human exposure, only occupational exposure of shift workers should, at this moment in time, be taken into consideration in LCA. In the case of biodiversity, a large body of evidence provides accurate information on the way to model the exposure-response pathway, showing that artificial light has the potential to significantly disrupt ecosystems (see e.g., Hölker et al., 2010; Rodríguez et al., 2012; Gaston et al., 2013). Some open questions require attention, due to the lack of a common mechanistic framework and of general principles (Hölker et al., 2010).

Focusing on the methodological aspects of LCA, it would be technically possible to record a sound, RF-EMF, and light emissions in an inventory table, in relation with the functional unit under study. In all cases, however, a consistent body of information would need to be registered for each elementary flow about the exact context of the emissions. This particular approach may differentiate these emissions from other flows in LCA, if we compare it to the common practice for toxic substances for which the specification of the emission compartment may deal with limited extra information (e.g., high or low population; Frischknecht et al., 2005). Until the moment that a vast amount of information would be stored in the commonly used LCA databases about possible inventory flows, LCA practitioners would have to deal with such challenging tasks. This approach may be feasible for local studies, dealing with just a few elementary flows, but may prove challenging when the system 
under study is more complex, as is typically the case of most LCA studies. More, and more detailed information would be needed for thousands of basic processes and flows. This consideration has to be taken into account also in view of the current tendency of highlyregional and highly-spatial explicit characterization factors. While giving the possibility of portraying any possible context of emission, and exposure, these developments may yet clash with the reality of a limited visibility of flows and processes for a life cycle that spans over a global system. The solution of the LCI problem is key to the effective use of an impact assessment model. The possibility of calculating CF by considering average conditions representative of regions of the world, or of the entire globe, may contribute to control these limitations. The recent work by de Baan et al. (2013) provides an interesting application of the average approach for the case of the impacts of land use. The determination of archetypes of typical contexts of emission, though increasing uncertainty, will certainly help the users towards this goal.

At the LCIA phase, the good knowledge available of the physics of waves for all of the three impact categories considered allows to model the path between the emission compartment and the exposure compartment. This also includes the modelling of the possible attenuations and local conditions (e.g., temperature, humidity; see Cucurachi and Heijungs, 2014 for the case of sound emissions). We saw in Section 3 that the knowledge of the mechanisms that relate the fate and exposure factors to a possible effect factor and, eventually, damage factor (Curran, 2012) are not always clear. An issue at this stage may determine a lack of significance of the model, thus suggest that it should not be taken into consideration given the knowledge that it is available at the current state. This will hamper the effective use also of a methodology otherwise rigorously developed. Developments in the understatement of the mechanisms of exposure-effect-damage will be necessary for a suitable model development. For the development of an impact assessment model, it is also necessary to have sufficient information on the background exposure levels, i.e. spatially and temporally, before any functional unit involving the emissions under consideration is considered. In the examples considered, while such information is available for the case of noise in the form of noise maps and for ELP in the form of light pollution maps, only recently it is available in the context of RF-EMF at the sole demographical level for Europe (Gajšek et al., 2013).

Based on such findings, in both the cases of RF-EMF and ELP we provide evidence that the LCI phase could be modelled, and the knowledge of the physics of waves would allow representing the physical propagation of waves, their attenuation and relationship to a functional unit. The LCIA modelling would, however, stop at the fate phase since no clear mechanisms are available to explain the specific impacts of each stressor on any target. For the case of noise, on the other hand, it is possible to define for human targets the complete impact pathway to the midpoint level of LCIA modelling.

In the case of the impacts on biodiversity, the current metrics used in LCA do not seem to provide a sufficient accurate measure to be matched to those mechanisms that are known. A paradigm-shift towards a species-by-species approach would be needed to consider only those impacts that are clearly known and proven, therefore bringing LCA to a rather different approach than the potential risk of global loss of biodiversity that is currently preached for in the community. The use of biodiversity indicators (e.g., mean species abundance of original species as in Alkemade et al., 2009) calculated for a specific biome (de Baan et al., 2012), has to be complemented with the specialist knowledge of the mechanisms existing at a specific species level. The effectiveness and the feasibility of such an approach need to be further studied, due to the considerable amount of data to be gathered, analysed, and processed.

\section{Conclusions}

The proposed framework allows to judge to which impacts to give priority in LCA. The analysis of the three unusual impacts taken into consideration provided sufficient information to evaluate the possibility to include them in LCA, given their importance in a number of relevant life cycles. The necessary modelling effort differs across the three categories, as does the knowledge of the seriousness of the effects and the clarity of the underlying mechanisms. This clearly puts a priority for research towards impact categories with compatible characteristics. Other tools rather than LCA need to be used until then, and possibly preferred, if a highly specific local study has to be conducted.

We showed that the inclusion of such categories may not be constrained neither by the complex physical principles that are at the basis of the relative sciences, nor by the specificity of the structure of LCA. The overview of some basic elements of the computational structure of LCA, has defined some criteria for the development of new impact assessment models. For the emergent impacts here presented, it seems sensible to say that we are not incurring in what Udo de Haes (2006) has called the 'Cinderellaeffect', thus we are not physically squeezing the physics of waves to the needs of LCA, or vice versa. Though some attention is still required at the $\mathrm{LCI}$ phase due to the type of information that needs to be gathered and stored, we can conclude that there are reasonable and scientific solutions to define elementary flows. What requires more attention is the knowledge that we have at this moment in time of the mechanisms that determine an effect, which are fundamental to define a characterization model. This clearly puts a priority for research towards noise impacts and ecologicallight impacts, rather than on RF-EMF impacts. Other tools rather than LCA, need to be used until then and possibly preferred if a highly specific local study has to be conducted.

The expansion of LCA to include complex impacts, such as the ones dealt with in this paper, may determine a barrier to practitioners lacking a specialized knowledge of the literature and mechanisms that determined the modelling of the impact assessment models. A detailed knowledge of a characterization model will be increasingly required if LCA expands and deepens its focus by incorporating newly available scientific evidence. This work may be considered an integral part of the development and improvement of the LCA framework.

\section{Acknowledgements}

The authors would like to thank the anonymous reviewers who gave a number of valuable remarks to improve the manuscript. A special thanks to Tonja van Gorp and Coen van der Giesen for the interesting exchange of ideas that improved the earlier versions of the paper.

\section{References}

Alkemade, R., van Oorschot, M., Miles, L., Nellemann, C., Bakkenes, M., ten Brink, B. 2009. GLOBIO3: a framework to investigate options for reducing global terrestrial biodiversity loss. Ecosystems 12 (3), 374-390.

Althaus, H.J., de Haan, P., Scholz, R.W., 2009. Traffic noise in LCA. Int. J. LCA 14 (6), 560-570.

Baan, R., Grosse, Y., Lauby-Secretan, B., El Ghissassi, F., Bouvard, V., BenbrahimTallaa, L., Straif, K., 2011. Carcinogenicity of radiofrequency electromagnetic fields. Lancet Oncol. 12 (7), 624-626.

Baliatsas, C., Van Kamp, I., Bolte, J., Schipper, M., Yzermans, J., Lebret, E., 2012. Nonspecific physical symptoms and electromagnetic field exposure in the general population: can we get more specific? A systematic review. Environ. Int. 41, 1528.

Barber, J.R., Crooks, K.R., Fristrup, K.M., 2010. The costs of chronic noise exposure for terrestrial organisms. Trends Ecol. Evol. 25 (3), 180-189. 
Bare, J.C., Gloria, T.P., 2008. Environmental impact assessment taxonomy providing comprehensive coverage of midpoints, endpoints, damages, and areas of protection. J. Clean. Prod. 16 (10), 1021-1035.

Bedrosian, T.A., Vaughn, C.A., Galan, A., Daye, G., Weil, Z.M., Nelson, R.J., 2013. Nocturnal light exposure impairs affective responses in a wavelengthdependent manner. J. Neurosci. 33 (32), 13081-13087.

Bee, M.A., Swanson, E.M., 2007. Auditory masking of anuran advertisement calls by road traffic noise. Anim. Behav. 74 (6), 1765-1776.

Bierman, A., 2012. Will switching to LED outdoor lighting increase sky glow? Light. Res. Technol. 44 (4), 449-458.

Brumm, H., 2004. The impact of environmental noise on song amplitude in a territorial bird. J. Anim. Ecol. 73 (3), 434-440.

Bryson, J.J., Ando, Y., Lehmann, H., 2007. Agent-based modelling as scientific method: a case study analysing primate social behaviour. Philos. Trans. R. Soc. Biol. Sci. 362 (1485), 1685-1699.

Chan, A.Y., Blumstein, D.T., 2012. Anthropogenic noise's first reverberation into community ecology. Proc. R. Soc. Biol. Sci. 279 (1739), 2725-2726.

Cinzano, P., Falchi, F., Elvidge, C.D., 2001. The first world atlas of the artificial night sky brightness. Mon. Not. R. Astron. Soc. 328 (3), 689-707.

Cruz-Castro, L., Sanz-Menéndez, L., 2005. Politics and institutions: European parliamentary technology assessment. Technol. Forecast. Soc. Change 72 (4), 429-448.

Cucurachi, S., Heijungs, R., 2014. Characterisation factors for life cycle impact assessment of sound emissions. Sci. total Environ. 468-469, 280-291.

Cucurachi, S., Heijungs, R., Ohlau, K., 2012. Towards a general framework for including noise impacts in LCA. Int. J. LCA 17 (4), 471-487.

Curran, M.A. (Ed.), 2012. Life Cycle Assessment Handbook: a Guide for Environmentally Sustainable Products. Wiley-Scrivener.

de Baan, L., Alkemade, R., Koellner, T., 2012. Land use impacts on biodiversity in LCA: a global approach. Int. J. LCA, 1-15.

de Baan, L., Mutel, C.L., Curran, M., Hellweg, S., Koellner, T., 2013. Land use in life cycle assessment: global characterization factors based on regional and global potential species extinction (open access). Environ. Sci. Technol. 47, 9281-9290.

EC-JRC, 2010a. Analysis of Existing Environmental Impact Assessment Methodologies for Use in Life Cycle Assessment-Background Document. ILCD Handbook-International Reference Life Cycle Data System. European Union. At: http://lct.jrc.ec.europa.eu/assessment/assessment/projects\#consultation_ impact (accessed January 2013)

EC-JRC, 2010b. Framework and Requirements for LCIA Models and Indicators. ILCD Handbook-International Reference Life Cycle Data System, European Union EUR24586EN, ISBN 978-92-79-17539-8. At: http://lct.jrc.ec.europa.eu/ assessment/assessment/projects\#consultation impact (accessed January 2013).

EC-JRC, 2011. Recommendations Based on Existing Environmental Impact Assessment Models and Factors for Life Cycle Assessment in European Context. ILCD Handbook-International Reference Life Cycle Data System, European Union EUR24571EN, ISBN 978-92-79-17451-3. At: http://lct.jrc.ec.europa.eu/ assessment/assessment/projects\#consultation_impact (accessed January 2013).

Eckel-Mahan, K., Sassone-Corsi, P., 2013. Metabolism and the circadian clock converge. Physiol. Rev, 93 (1), 107-135.

Ekvall, T., Weidema, B.P., 2004. System boundaries and input data in consequential life cycle inventory analysis. Int. J. LCA 9 (3), 161-171.

Fewtrell, J.L., McCauley, R.D., 2012. Impact of air gun noise on the behaviour of marine fish and squid. Mar. Pollut. Bull. 64 (5), 984-993.

Feychting, M., Ahlbom, A., Kheifets, L., 2005. EMF and health. Annu. Rev. Public Health 26, 165-189.

Fonken, L.K., Workman, J.L., Walton, J.C., Weil, Z.M., Morris, J.S., Haim, A., Nelson, R.J. 2010. Light at night increases body mass by shifting the time of food intake. Proc. Natl. Acad. Sci. 107 (43), 18664-18669.

Francis, C.D., Kleist, N.J., Ortega, C.P., Cruz, A., 2012. Noise pollution alters ecological services: enhanced pollination and disrupted seed dispersal. Proc. R. Soc. B 279 2727-2735.

Frischknecht, R., Braunschweig, A., Hofstetter, P., Suter, P., 2000. Human health damages due to ionising radiation in life cycle impact assessment. Environ. impact. Asses. Rev. 20 (2), 159-189.

Frischknecht, R., Jungbluth, N., Althaus, H.J., Doka, G., Dones, R., Heck, T., Spielmann, M., 2005. The ecoinvent database: overview and methodological framework (7 pp). Int. J. LCA 10 (1), 3-9.

Fritschi, L., Brown, L., Kim, R., Schwela, D., Kephalopolous, S., 2011. Burden of disease from environmental noise: Quantification of healthy life years lost in Europe. Available online at: http://www. who.int/quantifying_ehimpacts/publications/ e94888/en (accessed on: 2.7.13.).

Gajšek, P., Ravazzani, P., Wiart, J., Grellier, J., Samaras, T., Thuróczy, G., 2013. Electromagnetic field exposure assessment in Europe radiofrequency fields (10 MHz-6 GHz. J. Expo. Sci. Environ. Epidemiol. http://dx.doi.org/10.1038/ jes.2013.40

Gaston, K.J., Bennie, J., Davies, T.W., Hopkins, J., 2013. The ecological impacts of nighttime light pollution: a mechanistic appraisal. Biol. Rev, 88, 912-927.

Geels, F.W., Schot, J., 2007. Typology of sociotechnical transition pathways. Res. Policy 36 (3), 399-417.

Guinée, J.B., Heijungs, R., Huppes, G., Zamagni, A., Masoni, P., Buonamici, R., Rydberg, T., 2010. Life cycle assessment: past, present, and future. Environ. Sci. Technol. 45 (1), 90-96.

Haim, A., Portnov, B.A., 2013. Light Pollution as a New Risk Factor for Human Breast and Prostate Cancers. Springer.

Halfwerk, W., Holleman, L.J., Lessells, C.K., Slabbekoorn, H., 2011. Negative impact of traffic noise on avian reproductive success. J. Appl. Ecol. 48 (1), 210-219.
Hauschild, M.Z., Goedkoop, M., Guinée, J., Heijungs, R., Huijbregts, M., Jolliet, O. Pant, R., 2013. Identifying best existing practice for characterization modelling in life cycle impact assessment. Int. J. LCA 18 (3), 683-697.

Heijungs, R., Suh, S., 2002. The Computational Structure of Life Cycle Assessment vol. 11. Springer.

Heijungs, R., Guinee, J.B., Huppes, G., Lankreijer, R.M., Udo de Haes, H.A., Wegener Sleeswijk, A., Ansems, A.M.M., Eggels, P.G., van Duin, R., de Goede, H.P., 1992 Environmental Life Cycle Assessment of Products. I.Guide, October 1992. Il. Backgrounds, October 1992. CML, Leiden, 226 pp.

Hölker, F., Wolter, C., Perkin, E.K., Tockner, K., 2010. Light pollution as a biodiversity threat. Trends Ecol. Evol. 25 (12), 681-682.

Hollander, A.E.D., Melse, J.M., Lebret, E., Kramers, P.G., 1999. An aggregate public health indicator to represent the impact of multiple environmental exposures. Epidemiol. Baltimore 10 (5), 606-617.

Huijbregts, M.A., Schöpp, W., Verkuijlen, E., Heijungs, R., Reijnders, L., 2000 Spatially explicit characterization of acidifying and eutrophying air pollution in life-Cycle assessment. J. Ind. Ecol. 4 (3), 75-92.

Huijbregts, M.A., Hellweg, S., Frischknecht, R., Hungerbühler, K., Hendriks, A.J., 2008. Ecological footprint accounting in the life cycle assessment of products. Ecol. Econ. 64 (4), 798-807.

Huijbregts, M.A., Hellweg, S., Hertwich, E., 2011. Do we need a paradigm shift in life cycle impact assessment? Env. Sci. Tech. 45 (9), 3833-3834.

IARC, The International Agency for Research on Cancer, 2013. Monograph : Nonionizing Radiation,Part 2: Radiofrequency Electromagnetic Fields, vol. 102. Available online at: http://monographs.iarc.fr/ENG/Monographs/vol102 mono102.pdf (accessed 30.08.13.)

ICNIRP (International Commission on Non-ionising Radiation Protection), 1998. Guidelines for limiting exposure to time-varying electric, magnetic, and electromagnetic fields (up to $300 \mathrm{GHz}$ ). Health Phys. 74 (4), 494-522.

ICNIRP (International Commission on Non-ionising Radiation Protection), 2010. Statement-guidelines for limiting exposure to time-varying electric, magnetic and electromagnetic fields (1 Hz-100 kHz). Health Phys. 99, 818-836.

ISO, 2006. ISO 14044:2006 Environmental Management-Life Cycle Assessment-Requirements and Guidelines. International Standards Organization.

Jolliet, O., Müller-Wenk, R., Bare, J., Brent, A., Goedkoop, M., Heijungs, R. Weidema, B., 2004. The LCIA midpoint-damage framework of the UNEP/SETAC life cycle initiative. Int. J. LCA 9 (6), 394-404.

Klöpffer, W., 2012. Life cycle sustainability assessment of products. Int. J. Life Cycle Ass 13 (2), 89-94.

Kocifaj, M., 2007. Light-pollution model for cloudy and cloudless night skies with ground-based light sources. Appl. Opt. 46 (15), 3013-3022.

Kocifaj, M., 2008. Light pollution simulations for planar ground-based light sources. Appl. Opt. 47 (6), 792-798.

Kocifaj, M., 2011. A numerical experiment on light pollution from distant sources. Mon. Not. R. Astron. Soc. 415 (4), 3609-3615.

Kyba, C.C., Ruhtz, T., Fischer, J., Hölker, F., 2011. Cloud coverage acts as an amplifier for ELP in urban ecosystems. PLoS One 6 (3), e17307.

Lerchl, A., 2011. Animal studies on growth and development. Prog. Biophys. Mol Biol. 107 (3), 404-407.

Longcore, T., Rich, C., 2004. ELP. Front. Ecol. Environ. 2 (4), 191-198.

Marcheva, B., Ramsey, K.M., Buhr, E.D., Kobayashi, Y., Su, H., Ko, C.H., Bass, J., 2010 Disruption of the clock components CLOCK and BMAL1 leads to hypoinsulinaemia and diabetes. Nature 466 (7306), 627-631.

Møller, A.P., Mousseau, T.A., 2013. The effects of natural variation in background radioactivity on humans, animals and other organisms. Biol. Rev 88 (1), 226-254.

Müller-Wenk, R., 2004. A method to include in LCA road traffic noise and its health effects. Int. J. LCA 9 (2), 76-85.

Murray, C.J.L., 1994. Quantifying the burden of disease: die technical basis for disability-adjusted life years. Bull. W.H.O 72 (3), 429-445.

Navara, K.J., Nelson, R.J., 2007. The dark side of light at night: physiological epidemiological, and ecological consequences. J. Pineal Res. 43 (3), 215-224.

Owen, M.A., Swaisgood, R.R., Czekala, N.M., Steinman, K., Lindburg, D.G., 2004 Monitoring stress in captive giant pandas (Ailuropoda melanoleuca): behavioural and hormonal responses to ambient noise. Z. Biol. 23 (2), 147-164.

Parris, K.M. Schneider, A., 2009. Impacts of traffic noise and traffic volume on birds of roadside habitats. Ecol. Soc. 14 (1), 29.

Passchier-Vermeer, W., Passchier, W.F., 2000. Noise exposure and public health Environ. Health Perspect. 108 (Suppl 1), 123.

Pauley, S.M., 2004. Lighting for the human circadian clock: recent research indicates that lighting has become a public health issue. Med. Hypotheses 63 (4), 588-596.

Perkin, E.K., Hölker, F., Richardson, J.S., Sadler, J.P., Wolter, C., Tockner, K., 2011. The influence of artificial light on stream and riparian ecosystems: questions, challenges, and perspectives. Ecosphere 2 (11) art122.

Popper, K.R., 1963. Conjectures and refutations, vol. 28. Routledge \& Kegan Paul London.

Potting, J., Schöpp, W., Blok, K., Hauschild, M., 1998. Site-dependent life-cycle impact assessment of acidification. J. Ind. Ecol. 2 (2), 63-87.

Rich, C., Longcore, T., 2006. Ecological Consequences of Artificial Night Lighting. Island Press.

Rodríguez, A., Rodríguez, B., Curbelo, A.J., Pérez, A., Marrero, S., Negro, J.J., 2012 Factors affecting mortality of shearwaters stranded by light pollution. Anim. conserv. 15 (5), 519-526.

Röösli, M., Frei, P., Mohler, E., Braun-Fahrländer, C., Bürgi, A., Fröhlich, J., Egger, M., 2008. Statistical analysis of personal radiofrequency electromagnetic field measurements with nondetects. Bioelectromagnetics 29 (6), 471-478. 
Rosenbaum, R.K., Margni, M., Jolliet, O., 2007. A flexible matrix algebra framework for the multimedia multipathway modelling of emission to impacts. Environ. Int. 33 (5), 624-634.

Russell, A.W., Vanclay, F.M., Aslin, H.J., 2010. Technology assessment in socia context: the case for a new framework for assessing and shaping technological developments. Impact Assess. Proj. Apprais. 28 (2), 109-116.

Schernhammer, E.S., Schulmeister, K., 2004. Melatonin and cancer risk: does light at night compromise physiologic cancer protection by lowering serum melatonin levels? Br. J. cancer 90 (5), 941-943.

Stewart, J., McManus, F., Rodgers, N., Weedon, V., Bronzaft, A., 2012. Why Noise Matters. Routledge.

Swarr, T.E., Hunkeler, D., Klöpffer, W., Pesonen, H.L., Ciroth, A., Brent, A.C., Pagan, R., 2011 Environmental life-cycle costing: a code of practice. Int. J. LCA 16 (5), 389-391.

Tähkämö, L., Bazzana, M., Ravel, P., Grannec, F., Martinsons, C., Zissis, G., 2013. Life cycle assessment of light-emitting diode downlight luminaire-a case study. Int. J. LCA, 1-10.
Udo de Haes, H., 2006. How to approach land use in LCIA or, how to avoid the Cinderella effect? Int. J. LCA 11, 219-221.

Udo de Haes, H.A., Finnveden, G., Goedkoop, M., Hauschild, M., Hertwich, E. Hofstetter, P., Klöpffer, W., Krewitt, W., Lindeijer, E., Jolliet, O., Mueller-Wenk, R., Olsen, S., Pennington, D., Potting, J., Steen, B., 2002. Life Cycle Impact Assessment: Striving Towards Best Practice. SETAC Press, Pensacola, ISBN 1-88061154-6.

Udo de Haes, H.A.U., Heijungs, R., Suh, S., Huppes, G., 2004. Three strategies to overcome the limitations of life-cycle assessment. J. Ind. Ecol. 8 (3), 19-32.

van Deventer, E., van Rongen, E., Saunders, R., 2011. WHO research agenda for radiofrequency fields. Bioelectromagnetics 32 (5), 417-421.

Warren, P.S., Katti, M., Ermann, M., Brazel, A., 2006. Urban bioacoustics: it's not just noise. Anim. Behav. 71 (3), 491-502. 